\title{
Assessing the effect of different treatments on decomposition rate of dairy manure
}

Tariq M. Khalii ${ }^{1 *}$, Stewart S. Higgins ${ }^{1}$, Pius M. Ndegwa ${ }^{1}$, Craig S. Frear ${ }^{2}$, Claudio O. Stöckle ${ }^{1}$

${ }^{1}$ Department of Biological Systems Engineering, Washington State University, Pullman, WA 99164

${ }^{2}$ Regenis Inc., 6920 Salashan Pkwy, Ferndale, WA 98248

* Corresponding author. Tel.: +1 (509) 715-7527, Fax: +1 (509) 335-2722

Email address: tariqmahmood.khalil@wsu.edu

(C) 2016. This manuscript version is made available under the Elsevier user license http://www.elsevier.com/open-access/userlicense/1.0/ 
Abstract

Confined animal feeding operations (CAFOs) contribute to greenhouse gas emission, but the magnitude of these emissions as a function of operation size, infrastructure, and manure management are difficult to assess. Modeling is a viable option to estimate gaseous emission and nutrient flows from CAFOs. These models use a decomposition rate constant for carbon mineralization. However, this constant is usually determined assuming a homogenous mix of manure, ignoring the effects of emerging manure treatments. The aim of this study was to measure and compare the decomposition rate constants of dairy manure in single and three-pool decomposition models, and to develop an empirical model based on chemical composition of manure for prediction of a decomposition rate constant. Decomposition rate constants of manure before and after an anaerobic digester (AD), following coarse fiber separation, and fine solids removal were determined under anaerobic conditions for single and three-pool decomposition models. The decomposition rates of treated manure effluents differed significantly from untreated manure for both single and three-pool decomposition models. In the single-pool decomposition model, AD effluent containing only suspended solids had a relatively high decomposition rate of $0.060 \mathrm{~d}^{-1}$, while liquid with coarse fiber and fine solids removed had the lowest rate of $0.013 \mathrm{~d}^{-1}$. In the three-pool decomposition model, fast and slow decomposition rate constants $\left(0.25 \mathrm{~d}^{-1}\right.$ and $0.016 \mathrm{~d}^{-}$ ${ }^{1}$ respectively) of untreated $A D$ influent were also significantly different from treated manure fractions. A regression model to predict the decomposition rate of treated dairy manure fitted well $\left(R^{2}=0.83\right)$ to observed data.

Keywords: Dairy manure; Manure treatments; Decomposition rate constant; Carbon mineralization; Whole farm modeling 


\section{Introduction}

During the past three decades a shift in dairy operations from free grazing to confined animal feeding operations (CAFOs) has raised many questions concerning natural resource contamination (Lanyon, 1994; Spellman \& Whiting, 2007). From 1990 to 2011 , GHG emission from dairy farms increased by $111 \%$ (EPA, 2013). This is mainly due to manure storage in lagoons under anaerobic conditions before application to croplands, emitting non- $\mathrm{CO}_{2} \mathrm{GHG}$ emissions, such as methane $\left(\mathrm{CH}_{4}\right)$, with higher global warming potentials. In the United States, about $37 \%$ of the $\mathrm{CH}_{4}$ emission on a dairy CAFO is from manure management due to anaerobic decomposition of dairy manure (USDA, 2011). A shift in manure handling also increased nitrogen (N) losses up to 65 percent (NRCS, 2015), mainly in the form of ammonia, which is a precursor for formation of fine particulate matter (Ndegwa et al., 2008). Dairy manure is usually applied to the nearby fields due to associated cost if hauled to distant locations. As a result, manure nutrients can be in surplus relative to the assimilative capacities of dairy crop lands (Heathwaite et al., 2000; Sims et al. 2005). Losses of these excess nutrients particularly $N$ and phosphorous (P), can cause eutrophication (De Jong et al., 2009; Lanyon, 1994).

In 1999, EPA and USDA jointly issued the Unified National Animal Feeding Operation strategy plan to protect the environment. To help CAFO managers comply with regulations, researchers are studying technological options to reduce GHG emission from manure management. Various traditional and emerging techniques are available for manure treatments to reduce emission and nutrient overloading in dairy lands. From an emissions standpoint, anaerobic digestion (AD) has become a common approach to mitigate odor and GHG emissions while also reducing solids content during the 
biodegradation process (Novak et al., 2011). Post-digestion, the screening of recalcitrant coarse fibers for an additional reduction of solids loading into lagoons (Chastain et al., 2001; Møller et al., 2000), is also a common strategy. Beyond simple coarse solids separation, dairies are also moving to advanced fine solids separation using technologies such as decanting centrifuges, polymer belt press systems, and dissolved air flotation (DAF) (Burton, 2007, Menke at al., 2005). Fine solids separation is credited with significant reductions in organic $\mathrm{P}$ and $\mathrm{N}$ from the wastewater (Vanotti and Hunt, 1999). Lastly, emerging technologies such as membrane nitrification/denitrification (MBR), vermifiltration, ammonia stripping, ultrafiltration/reverse osmosis, and evaporation are now being considered for incorporation and more complete recovery/removal of nutrients and salts from wastewater (BAO et al., 2012; Fu et al., 2009; Ledda et al., 2013; Uludag-Demirer et al., 2008).

To estimate emissions and nutrient fate from a whole farm perspective, modeling is a viable alternative to expensive, time consuming experimental studies. Models can be used to investigate the impact of manure treatment techniques on gaseous emission and nutrient fate from a whole farm perspective. Different models are available to estimate emissions from manure management and land application (Olesen et al., 2004; Phetteplace et al., 2001; Rotz et al., 2015; Li et al. 2012; Rotz et al., 2010; Stöckle et al., 2003; Uslar, 2010). Some of the models use emission factors, while others process-based models uses a decomposition rate constants for carbon mineralization. Literature values for the decomposition rate constant of bovine manure range from 0.011 to $0.072 \mathrm{~d}^{-1}$ (Murwira et al., 1990; Saviozzi et al., 1993; Tritt and Kang, 1991). This wide variation is attributed to different manure characteristics including but 
not limited to ratio of constituents (i.e. proteins, lipids, carbohydrates, and lignin) and prevailing experimental conditions. Manure decomposition rates from the literature are mainly calculated for homogenously mixed manure, without considering the effect of traditional and emerging manure treatments on decomposition rate. The decomposition rate of manure organic matter is dependent on the initial concentration of carbon and its biochemical composition (Thomsen et al., 2013), which is directly related to animal feed composition and solids reduction capacities of treatment units installed on a dairy facility (Møller et al., 2000).

Use of a single decomposition rate constant based on a homogenous manure mixture, therefore, is not likely to predict actual $C$ and $N$ mineralization from a lagoon if $A D$, solids separation, and nutrients recovery units are incorporated on a dairy CAFO facility. Determination of decomposition rates of treated dairy manure effluents is necessary for planning and optimizing the efficiencies of manure management systems, nutrient fate, and gaseous emission. Although there are many research studies focusing on decomposition rate constants of dairy manure in soils, and biochemical methane production (BMP) under anaerobic condition at higher temperature ranging from mesophilic to thermophilic, there is a lack of research on decomposition kinetics of dairy manure after different treatments and storage in lagoons at ambient conditions.

Dairy CAFO manure composition and treatment techniques may differ from farm to farm, which limits the use of decomposition rate constants calculated for a particular facility. Decomposition kinetics of manure organic matter under anaerobic conditions is a complex and time consuming process and requires up to $90 \mathrm{~d}$ or more incubation time (Kafle and Kim, 2012). Mathematical models with fast analytical methods allow quick 
prediction of decomposition rate constants and are very useful for predicting the BMP and biodegradability of biomass used in renewable energy production (Chandler et al., 1980; Lesteur et al., 2011). Since knowledge of the decomposition rate of dairy manure subject to different treatments is important for predicting gaseous emission from lagoons, development of a model for determining decomposition rate of treated manure, based on its constituents, greatly improves the accuracy of emissions predictions, without undertaking costly experiments.

To the best of our knowledge, this is the first study to examine the impact of traditional and emerging manure treatments on the decomposition rate constants of dairy manure. The main objective of this study was to evaluate the impact of different manure treatment techniques on decomposition of dairy manure effluents stored in lagoons under anaerobic conditions. The specific objectives were: (1) to derive the first order decomposition rate constants for single and three-pool decomposition models, and (2) develop an empirical model to predict the decomposition rate constant for single pool carbon kinetics.

\section{Materials and methods}

\subsection{Manure source}

Manure samples were collected at various points in the manure processing system in a commercial dairy operation located in Outlook, WA, USA. Figure 1 shows manure flow through different treatments and identifies the points where manure samples were collected. Grab samples at each point were collected when the entire system was operating at steady state (i.e. during representative flow across all of the unit operations 
inlet and outlets). Samples were collected in 5-gallons buckets, labeled, sealed and stored in $4^{\circ} \mathrm{C}$ a walk-in cooler. During later analysis, material in buckets were thoroughly mixed and sub-sampled into $2 \mathrm{~L}$ polyethylene bottles and stored at $4^{\circ} \mathrm{C}$ before analysis. Manure fractions included untreated AD influent (UT, 50\% diluted as-produced manure); $A D$ effluent, which was divided into two fractions, effluent containing only suspended particles (AD-liq) and settled solids removed from the AD effluent (AD-sett); screenseparated digested coarse fiber (CF); fine solids resulting from advanced solids DAF separation (FS); and effluent post $A D$, screen and DAF separation (CF/DAF-liq). $A D$ suspended and settleable solids were separated following the methodology used in Frear et al. (2011). UT, AD-liq, CF/DAF-liq and AD-sett were considered to be liquid/slurry fractions while CF and FS were considered to be solid fractions.

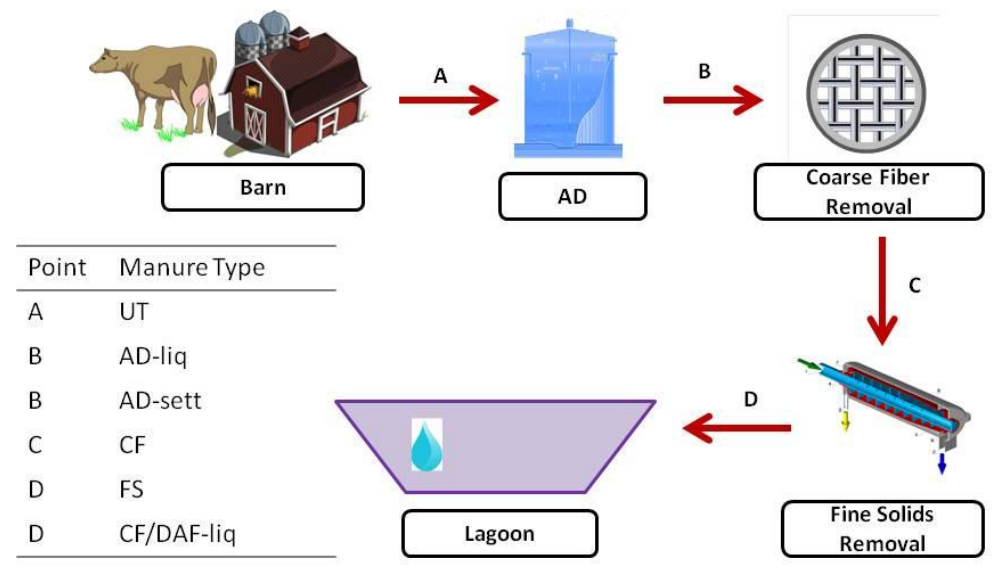

Figure 1. Manure treatment flow and manure collection points.

UT: Untreated influent; AD-liq: AD effluent containing suspended solids only; AD-sett: AD effluent settleable solids; CF/DAF-liq: AD effluent with coarse fiber and fine solid removed; FS: Manure fine solids; and CF: Coarse fiber 


\subsection{Analytical methods}

Total solids (TS, 2540B) and volatile solids (VS, 2540E) were determined according to standard procedures outlined in APHA (2005). Total ammonia nitrogen (TAN) and Total Kjehldahl nitrogen (TKN) were analyzed using a Tecator 2300 Kjeltec Analyzer (Eden Prairie, MN, USA). Structural carbohydrates and lignin were determined using the National Renewable Energy Laboratory Analytical Procedure NREL/TP-510-42618, while lipids were measured following the protocol described by Hara and Radin (1978). Protein was determined by subtracting TAN from TKN and multiplying by a factor of 6.25 (Pham et al., 2013). Total Carbon (CT) and $\mathrm{N}$ in manure fractions were determined using a TruSpec CHN analyzer (LECO, UK); resistant carbon ( $\mathrm{Cr}$ ) was determined by first performing acid hydrolysis on dry mass (Sollins et al., 1999) and then analyzing the hydrolysate for $\mathrm{C}$ using the TruSpec $\mathrm{CHN}$ analyzer. Biogas composition was analyzed using a gas chromatograph (GC) CP-3800 (Varian Inc, CA, USA) fitted with SilicaPLOT $50 \mathrm{~m} \times 0.53 \mathrm{~mm} \times 4 \mu \mathrm{m}$ and HayeSep Q 80/100 Mesh Silcosteel 18' x 1/8" columns..

\subsection{Anaerobic digestion test setup and design}

The experiment was conducted in a closed system for total recovery of $C$ mineralized during the incubation period. For $\mathrm{C}$ mineralization under anaerobic conditions, $45 \mathrm{~g}$ of each manure fraction were placed in an M-2020 incubator (Sheldon Inc, OR, USA) at 25 ${ }^{\circ} \mathrm{C}$ in triplicate using $250 \mathrm{ml}$ serum bottles equipped with rubber septa for gas sampling. To mimic the anaerobic conditions of lagoons while not limiting hydrolysis, de-ionized water of 40 and $80 \mathrm{ml}$ were added to fine solids and coarse fiber manure fractions, respectively. The reason for adding more water to coarse fiber was due to lower bulk density compared to fine solids. To promote microbial activity in the manure fraction, 
anaerobically digested sludge was collected from a dairy lagoon at Knott Dairy, Washington State University (Pullman, WA). Sludge samples were collected using a string and plastic bucket with small perforated bottom, metal weight was put inside the bucket that helped in sinking to the lagoon bottom. Sludge collected from three points in the lagoon were thoroughly mixed in 5-gallons bucket and sub-sampled in $2 \mathrm{~L}$ polyethylene bottles at $4^{\circ} \mathrm{C}$ before adding to the samples. The sludge to liquid manure volume ratio typically ranges from 6 to $18 \%$ in a dairy lagoon (Barker, 1996), so manure fractions were mixed with sludge 9:1 (Frear et al. 2011). Before sealing, each bottle was flushed with nitrogen gas for about three minutes to remove ambient air from the headspace. Incubated manure fractions were sampled for biogas every second day in the first month and then weekly using a syringe (Micro-Mate®, Italy). Gas samples were stored in evacuated Exetainers (W039, Labco Limited, UK) before carbonaceous gas analysis on the GC.

\subsection{Data analysis}

Carbon mineralized from each treatment was corrected for inoculum added to drive anaerobic decomposition. The mass-normalized portion of carbon emitted from sludge decomposition was measured by incubating sludge only, and this carbon was subtracted from each manure fraction. The volumetric concentration of methane and carbon dioxide measured by GC were converted into mass of $C$ per unit volume by applying the Ideal Gas Law (Robertson et al., 1999). The C mineralization curve was used to determine active and slow decomposition rate constants $\left(k_{a}\right.$ and $\left.k_{s}\right)$ as well as size of active and slow carbon pool $\left(C_{s}\right.$ and $\left.C_{a}\right)$ respectively following three pool decomposition model (Paul et al., 1999): 


$$
C_{\text {Mineralized }}=k_{a} C_{a} e^{\left(-k_{a} t\right)}+k_{S} C_{S} e^{\left(-k_{s} t\right)}+k_{r} C_{r} e^{\left(-k_{r} t\right)}
$$

where $t$ is time (days).

The size of $C_{s}$ pool was determined by subtracting $C_{a}$ and $C_{r}$ from $C_{T}$, while $C_{a}$, $k_{a}$, and $k_{s}$ were estimated through nonlinear regression using PROC NLIN of SAS with the Marquardt method (SAS Institute, 2008). Assuming a mean residence time of 1000 years for resistant carbon, the decomposition rate constant for the recalcitrant pool $\left(k_{r}\right)$ was set to $0.00000274 \mathrm{~d}^{-1}$ (Paul et al., 2001). Analysis of variance (ANOVA) was conducted for $k_{a}$ and $k_{s}$ obtained for each manure fraction using SAS PROC ANOVA (SAS Institute, 2008). Data were also fitted to a single pool model (Smith et al., 1980) for comparison with values available in the literature using

$$
C_{\text {Mineralized }}=C_{0} k e^{-k t}
$$

where $C_{0}$ is the concentration of $C$ in the sample and $k$ is the decomposition rate constant. Based on manure characteristics including carbohydrates, lignin, protein and lipids, a multiple regression analysis was carried out to develop an empirical model to predict decomposition rate values.

\section{Results and discussion}

\subsection{Dairy manure Characteristics}

Characteristics of manure fractions used in this experiment are listed in Table 1. The values of $\mathrm{C}, \mathrm{Cr}$, and $\mathrm{N}$ are reported on a dry mass basis. Among the liquid fractions of manure, untreated $50 \%$ diluted $A D$ influent had the highest TS and VS values $(7.3 \%$ 
and $78 \%$, respectively), while CF/DAF-liq had the lowest (1.4\% and $53 \%$, respectively). In solid/slurry fractions, however, CF had a lower value of TS compared to FS but had $31 \%$ more VS content than FS. Both CF/DAF-liq and CF had lower VS content compared to the rest of the manure fractions. The possible reason may be due to polymer with higher ash content added to the manure for fine solid removal. The CF/DAF-liq fraction had the lowest total $\mathrm{C}$ among all manure fractions, yet had the highest non-recalcitrant $\mathrm{C}$ fraction at $14 \%$. AD-liq fraction had the highest total $\mathrm{N}$ (3.56\%) followed by the CF/DAF-liq fraction (3.21\%), while the CF fraction had the lowest $\mathrm{N}$ content (2.26\%), among all manure fractions.

Table 1. Characteristics of dairy manure fractions used in this study. Values are on a dry mass basis with standard deviation in parenthesis.

\begin{tabular}{lccccc}
\hline Treatmentt & $\begin{array}{c}\text { Total Solids } \\
(\%)\end{array}$ & Volatile Solids (\%) & $\begin{array}{c}\text { Carbon } \\
(\%)\end{array}$ & $\begin{array}{c}\text { Resistant Carbon } \\
(\%)\end{array}$ & Nitrogen (\%) \\
\hline UT & $7.3(0.20)$ & $78(0.08)$ & $36(0.9)$ & $24(0.9)$ & $2.73(0.10)$ \\
AD-liq & $1.7(<0.003)$ & $62(0.004)$ & $29(0.2)$ & $13(0.2)$ & $3.56(0.03)$ \\
AD-sett & $11.4(0.002)$ & $68(0.02)$ & $34(0.2)$ & $24(0.7)$ & $2.61(0.04)$ \\
CF/DAF-liq & $1.4(<0.004)$ & $53(0.02)$ & $26(0.2)$ & $12(0.5)$ & $3.21(0.03)$ \\
FS & $34(<0.006)$ & $52(0.01)$ & $27(0.2)$ & $17(0.5)$ & $2.34(0.03)$ \\
CF & $30.0(0.003)$ & $84(0.003)$ & $42(0.4)$ & $31(0.1)$ & $2.26(0.03)$ \\
\hline
\end{tabular}

†UT: Untreated influent; AD-liq: AD effluent containing suspended solids only; AD-sett: AD effluent settleable solids; CF/DAF-liq: AD effluent with coarse fiber and fine solid removed; FS: Manure fine solids; and CF: Coarse fiber.

\subsection{Carbon mineralization}

Mass-normalized cumulative biogas produced by manure fractions on a wet mass basis ranged from 3.72 to $61.33 \mathrm{~mL} \mathrm{~g}^{-1}$ and 106.85 to $520.40 \mathrm{~mL} \mathrm{~g}^{-1}$ of biomass on a dry mass basis, respectively (Fig. 2). On wet mass basis UT produced the most biogas among liquid fractions, while the solid/slurry fraction CF produced the most when compared to AD-sett and FS. Initially FS produced more biogas than the rest of the manure fractions, but after day 28 FS produced less biogas than CF but still more than the other fractions. Higher production of biogas for UT and CF was apparently due to 
high total C and VS content compared to other liquid and solid fractions, though FS had high TS but lower total C and VS than coarse fiber (Table 1). Møller et al. (2004) presented similar results when analyzing the theoretical methane potential and biodegradability for different manure fractions. However when converted to dry mass basis using TS content in each fractions, AD-liq produced the highest biogas followed by CF/DAF-liq, while FS produced the least. These results were expected due to the presence of high labile $\mathrm{C}$ fractions.
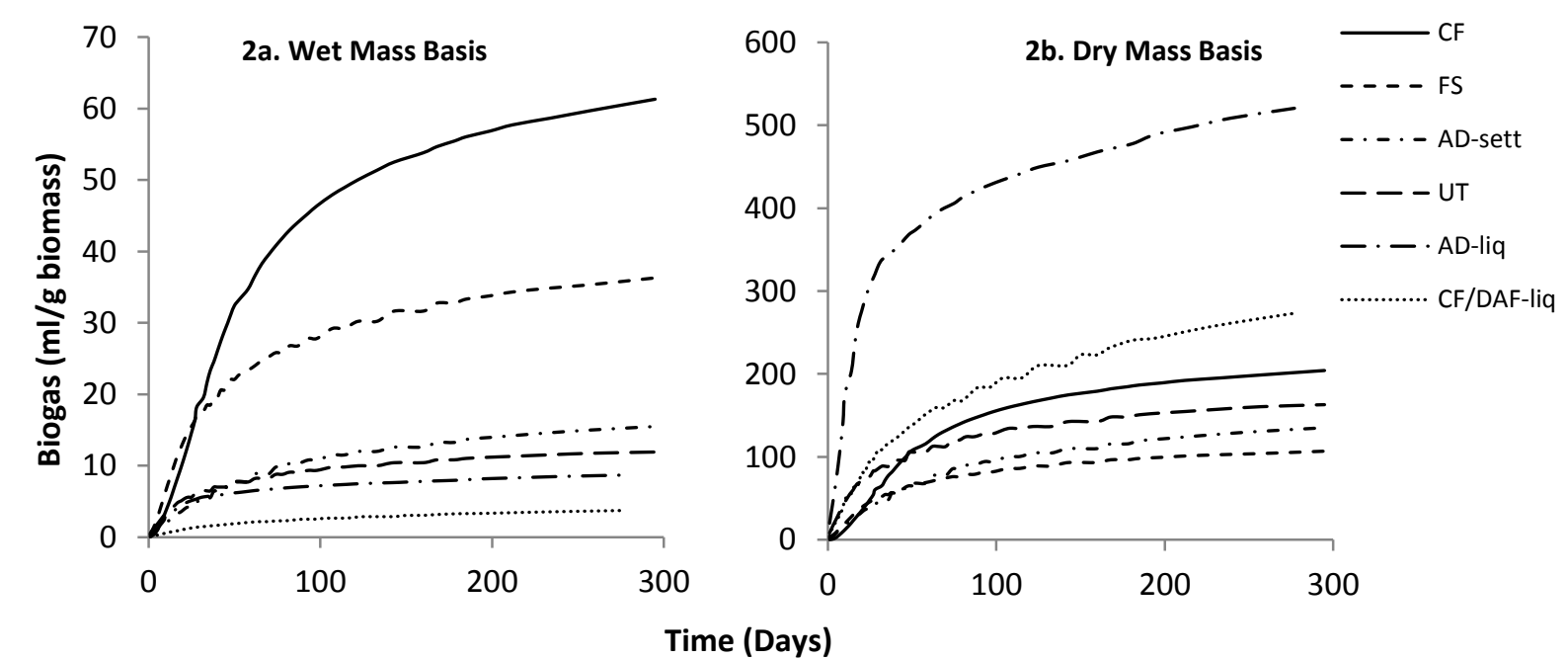

Figure 2. Biogas produced by different manure fractions. Observed values are mean of three replicates.

UT: Untreated influent; AD-liq: AD effluent containing suspended solids only; AD-sett: AD effluent settleable solids; CF/DAF-liq: $A D$ effluent with coarse fiber and fine solid removed; FS: Manure fine solids; and CF: Coarse fiber

\subsection{Decomposition rate constants}

Equations (1) and (2) fit the data well, predicting C fluxes that closely matched observed C fluxes (Figures 3 and 4). The decomposition rate constants are presented in Table 2 for both the three-pool and single-pool models. Among treated fractions, AD-liq had the highest single pool decomposition rate of $0.060 \mathrm{~d}^{-1}$, while CF/DAF-liq had the lowest value of $0.013 \mathrm{~d}^{-1}$ for single pool decomposition model. 
Table 2. Decomposition rate constants for single and three pool decomposition models. Values in columns with same letters in parenthesis are not significantly different.

\begin{tabular}{|c|c|c|c|c|}
\hline \multirow{3}{*}{ Treatment $†$} & \multicolumn{3}{|c|}{ Three Pool Model } & \multirow{3}{*}{$\begin{array}{c}\begin{array}{c}\text { Single Pool } \\
\text { Model }\end{array} \\
k \\
\mathrm{~d}^{-1} \times 10^{-2}\end{array}$} \\
\hline & $k_{a}$ & $k_{s}$ & $k_{r}$ & \\
\hline & $d^{-1}$ & $d^{-1}$ & $d^{-1} \times 10^{-6}$ & \\
\hline UT & $2.5 \times 10^{-1}(\mathrm{a})$ & $1.6 \times 10^{-2}(\mathrm{a})$ & 2.74 & 3.1 (a) \\
\hline AD-liq & $6.0 \times 10^{-2}(b)$ & $2.7 \times 10^{-6}(b)$ & 2.74 & $6.0(b)$ \\
\hline$A D$-sett & $1.2 \times 10^{-1}(\mathrm{c})$ & $1.2 \times 10^{-2}(\mathrm{c})$ & 2.74 & 1.4 (c) \\
\hline CF/DAF-liq & $1.3 \times 10^{-2}(b)$ & $2.8 \times 10^{-5}(b)$ & 2.74 & $1.3(\mathrm{c})$ \\
\hline FS & $2.8 \times 10^{-2}(b)$ & $1.0 \times 10^{-3}(b)$ & 2.74 & $2.8(d)$ \\
\hline CF & $1.9 \times 10^{-2}(b)$ & $2.7 \times 10^{-6}(b)$ & 2.74 & $1.9(\mathrm{e})$ \\
\hline
\end{tabular}

Subscript a, active pool of decomposition; s, slow pool of decomposition; r, recalcitrant or resistant pool of decomposition.

†UT: Untreated influent; AD-liq: AD effluent containing suspended solids only; AD-sett: AD effluent settleable solids; CF/DAF-liq: AD effluent with coarse fiber and fine solid removed; FS: Manure fine solids; and CF: Coarse fiber
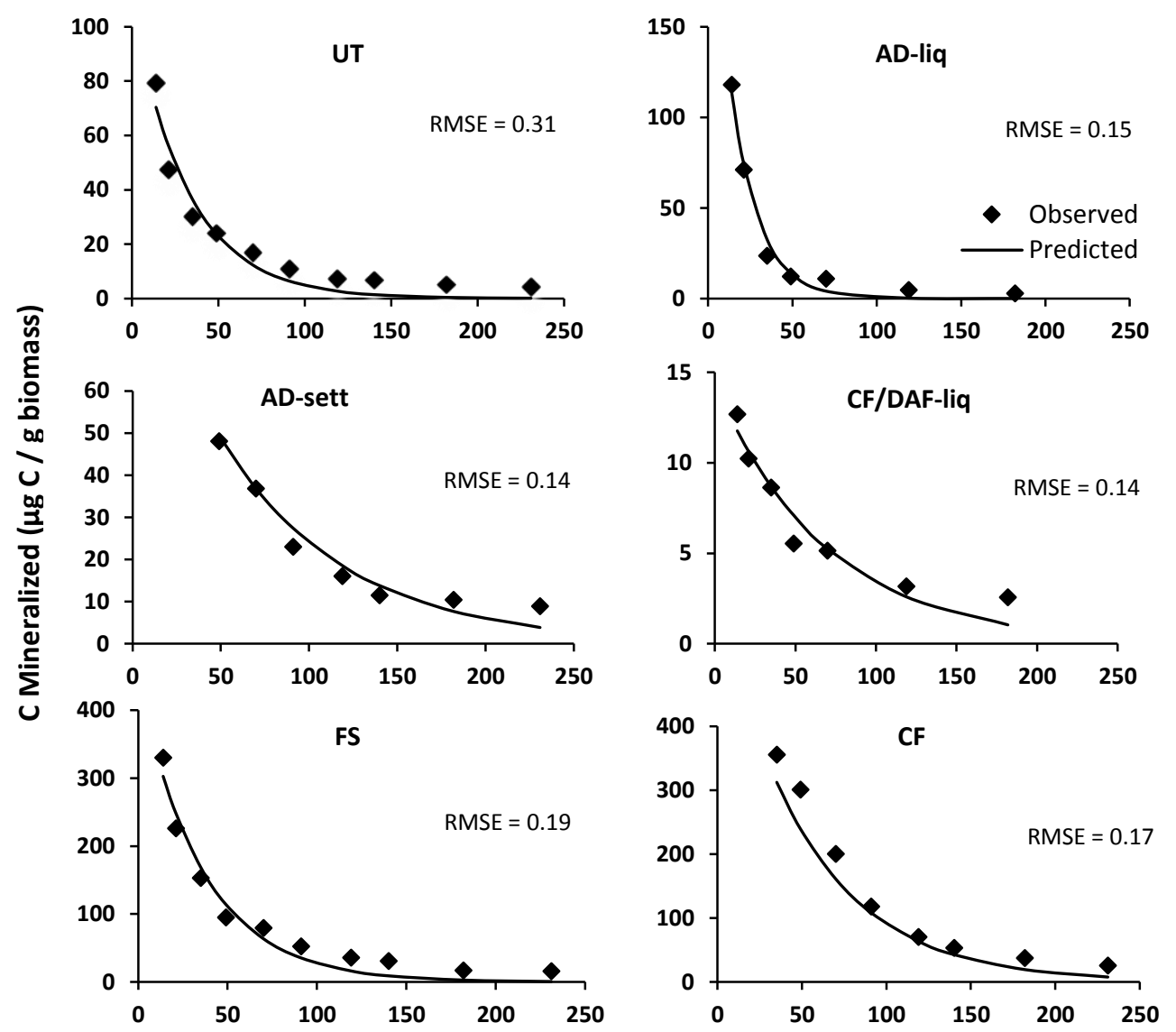

Figure 3. Decomposition of various dairy manure fractions in laboratory incubations when characterized using a single-pool model. Observed values are mean of three replicates.

UT: Untreated influent; AD-liq: AD effluent containing suspended solids only; AD-sett: AD effluent settleable solids; CF/DAF-liq: AD effluent with coarse fiber and fine solid removed; FS: Manure fine solids; and CF: Coarse fiber. Note different $y$-axis scales. 


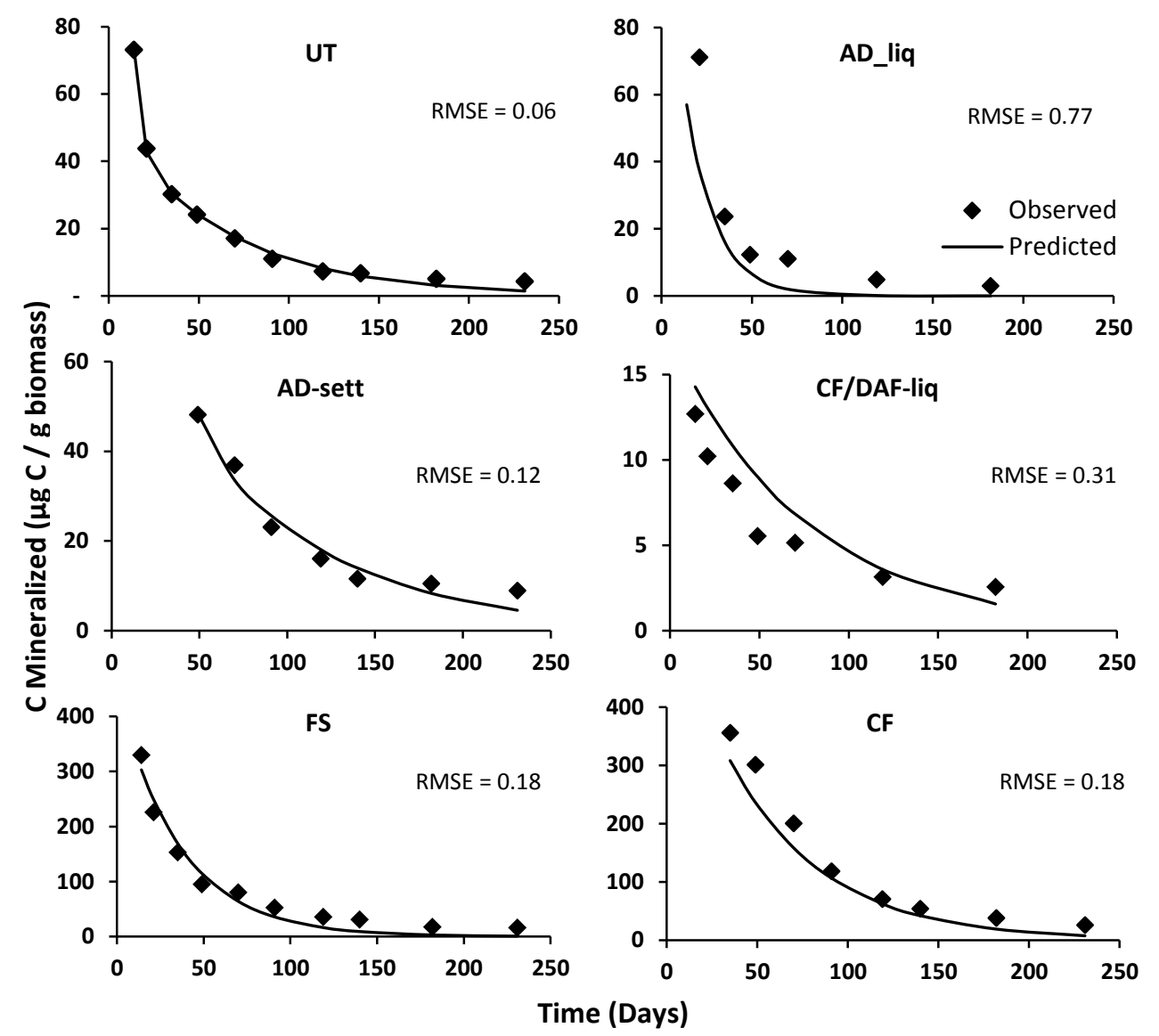

Figure 4. Decomposition of various dairy manure fractions in laboratory incubations when characterized using a three-pool model. Observed values are mean of three replicates.

UT: Untreated influent; AD-liq: AD effluent containing suspended solids only; AD-sett: AD effluent settleable solids; CF/DAF-liq: AD effluent with coarse fiber and fine solid removed; FS: Manure fine solids; and CF: Coarse fiber. Note different $y$-axis scales.

The ANOVA results show that $k_{a}$ and $k_{s}$ values for untreated UT, AD-liq and AD-sett were significantly different from each other. However, no significant difference was found between CF/DAF-liq and AD-liq. Nor was a difference found between decomposition rate for CF and FS in either fast or slow pool of decomposition. For ADliq and CF, nonlinear regression gives the same values for $\mathrm{ks}_{\mathrm{s}}$ and $\mathrm{k}_{\mathrm{r}}$, due to a very small slow-decomposing carbon pool compared to the labile and recalcitrant pools.

With the single pool model CF/DAF-liq had the lowest decomposition rate constant among all treatments containing solids concentration of less than $2 \%$, which was expected since the rate of substrate mineralization decreases with decreasing substrate 
concentration for a given biomass (Metcalf and Eddy, 2014). The decomposition rate for UT ( $50 \%$ diluted flushed manure) of $0.031 \mathrm{~d}^{-1}$ was within the reported range 0.016 to $0.088 \mathrm{~d}^{-1}$ reported in Tritt and Kang, (1991) for cow paunch manure first-order decay coefficient in which a single pool model was used.

In the three-pool model for UT, $k_{a}$ and $k_{s}$ were 0.25 and $0.02 \mathrm{~d}^{-1}$, respectively, with about more than $40 \%$ of the non-recalcitrant $C$ in the slow pool. These values of $k_{a}$ and $k_{s}$ were fairly close to 0.33 and $0.04 \mathrm{~d}^{-1}$ for the fast and slow pools reported in the NCSOIL model for residue decomposition in soil (Molina et al., 1983). Decomposition rate constant $k_{a}$ for AD-liq yielded $0.06 \mathrm{~d}^{-1}$ and was in close agreement with $0.074 \mathrm{~d}^{-1}$ reported in $\mathrm{Li}$ et al. (2012) for the labile pool of manure determined under aerobic conditions. The reason for this close proximity of decomposition rate constants for ADliq under aerobic and anaerobic conditions is due to the presence of easily hydrolysable compounds that decompose almost at the same rate under both aerobic and anaerobic conditions (Kristensen et al., 1995). For FS, CF, and AD-sett single-pool decomposition rate constants $\left(0.028,0.019\right.$, and $0.014 \mathrm{~d}^{-1}$, respectively) were lower than UT and AD-liq due to the presence of a high proportion of structural components (i.e. cellulose, hemicelluloses, and lignin) in these fractions so they decompose slower under anaerobic conditions due to initialization of hydrolysis and enzymatic activity (Kristensen et al., 1995).

\subsection{Empirical Model}

Current reported decomposition rate constants are based on efficiencies of $A D$ and solids separation (SS) units; however, solids reduction efficiencies of manure treatment methods may differ depending on their operational condition and solids reduction 
capabilities. Biochemical properties of manure can be used as predictors of decomposition rates. To predict decomposition rate values as a function of manure biochemical composition (Table 3), a stepwise regression was conducted to develop an empirical model. Values of cellulose, hemicelluloses, lignin, and lipids are reported on a dry mass basis, while protein is based on wet mass.

Table 3. Cellulose, hemicelluloses, lignin, lipids, and proteins content in manure fractions. Values in parenthesis are standard deviations.

\begin{tabular}{lccccc}
\hline Treatment $\dagger$ & $\begin{array}{c}\text { Cellulose } \\
(\%)\end{array}$ & $\begin{array}{c}\text { Hemicelluloses } \\
(\%)\end{array}$ & Lignin (\%) & Lipids (\%) & Proteins (mg/kg) \\
\hline UT & $20.64(2.71)$ & $12.98(2.64)$ & $13.96(0.23)$ & $4.10(0.33)$ & $8428(912)$ \\
AD-liq & $9.32(3.97)$ & $12.00(4.58)$ & $5.49(0.58)$ & $2.58(0.08)$ & $4358(339)$ \\
AD-sett & $16.22(4.61)$ & $9.92(2.97)$ & $18.52(1.42)$ & $1.77(0.23)$ & $5382(290)$ \\
CF/DAF-liq & $2.73(0.87)$ & $2.40(0.99)$ & $9.82(0.39)$ & $4.34(0.35)$ & $2897(213)$ \\
FS & $8.12(0.74)$ & $5.88(0.52)$ & $14.20(0.43)$ & $0.86(0.08)$ & $44(1.02)$ \\
CF & $26.36(2.74)$ & $16.08(2.74)$ & $32.15(0.27)$ & $1.14(0.08)$ & $37(0.23)$ \\
\hline
\end{tabular}

† UT: Untreated influent; AD-liq: AD effluent containing suspended solids only; AD-sett: AD effluent settleable solids; CF/DAF-liq: AD effluent with coarse fiber and fine solid removed; FS: Manure fine solids; and CF: Coarse fiber. SD values are in parenthesis.

For regression analysis only liquid/slurry fractions (UT, AD-liq, AD-sett, and CF/DAF-liq) of manure were considered, as manure solids (FS, and CF) are removed from manure stream entering lagoon for season long storage. The following equation was obtained with a $R^{2}$ value of 0.83 for estimating decomposition rate constant in terms of manure constituents using backward elimination:

$$
k=(41.89+2.36 \times \text { Hemicelluloses }-2.88 \times \text { lignin }) \times 10^{-3}
$$

Equation 3 is in close agreement with Chandler et al. (1980), who modeled the biodegradability of manure and different agricultural wastes as a function of the non degradable fibrous part of the substrate. As in our study, Buffiere et al. (2006) also showed a close relation of lignocellulosic materials on biodegradability of organic 
wastes. Triolo et al. (2011) found lignin to be the strongest predictor in a statistical model for BMP and biodegradability of manure and crop biomass that decomposed under anaerobic conditions at thermophilic temperature $\left(55^{\circ} \mathrm{C}\right)$. Cellulose, protein, and lipids did not significantly add to the equation. Another regression model for BMP prediction also found that the non-degradable part of manure was the most significant predictor $\left(p=0.026, R^{2}=0.85\right)$ using different animal manures at $36.5^{\circ} \mathrm{C}$ (Kafle and Chen, 2016).

The goodness of fit of the model (Equation 3) to the observed values was estimated using normalized mean error (NME), which is based on the principle of relative difference and is determined using the following relation:

$$
\operatorname{NME}(\%)=\frac{\sum_{1}^{n}\left|k_{p}-k_{o}\right|}{\sum_{1}^{n} k_{o}} \times 100
$$

where $k_{p}$ and $k_{o}$ are the respective model predicted and observed decomposition rates, and $\mathrm{n}$ is the number of observations. The comparison of observed and modeled predicted $\mathrm{k}$ values is shown in figure 5 for treated liquid and slurry manure fractions. The regression model using the lignocellusic part of the manure to estimate decomposition rate constant had the best fit to experimental data with a NME value of less than $22 \%$. 


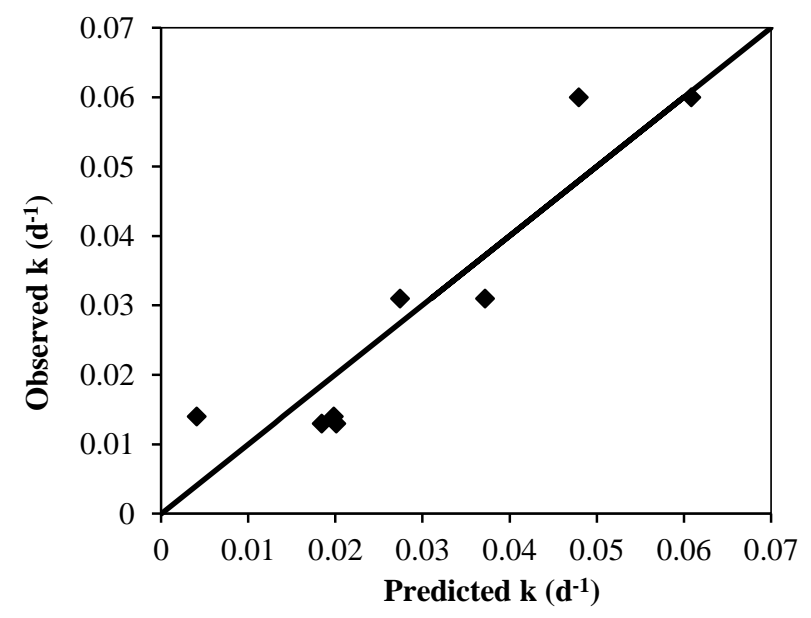

Figure 5. Observed decomposition rate determined using first order kinetic vs regression model predicted decomposition rate using the lignocellulosic part of manure as input parameter

\section{Conclusions}

This study provides evidence that manure treatment techniques alter manure characteristics in terms of TS and decomposition rates of effluent manure fractions. After manure treatment, the decomposition rate values of treated manure effluents differed significantly from untreated manure under both single- and three-pool decomposition models. Anaerobic digested manure effluent containing only suspended solids had a relatively high decomposition rate of $0.060 \mathrm{~d}^{-1}$, while anaerobic digested liquid manure fraction with coarse fiber and fine solids removed had the lowest decomposition rate of $0.013 \mathrm{~d}^{-1}$ compared to untreated $A D$ influent. In a three-pool decomposition model, the carbon mineralization rate for untreated manure $\left(k_{a}=0.25 d^{-1}\right.$ and $k_{s}=0.016 \mathrm{~d}^{-1}$ ) were significantly different than for treated manure effluents in both labile and slow pools. Specific decomposition rate values should, therefore, be used when $A D$ and SS treatments are part of the manure processing chain on a dairy facility. A regression model using manure composition as an input variable for decomposition rate constant fitted the measured data well $\left(R^{2}=0.83\right)$. Among manure constituents, the 
lignocellulosic part of manure was found to be the strongest predictor of manure decomposition rate. Accurate predictions of treated manure decomposition rate constants can be made using biochemical composition of substrate in lieu of long term batch studies.

\section{Acknowledgement}

This work was sponsored, in part, by USDA National Institute of Food and Agriculture (Contract Number 2012-6800219814), the US Environmental Protection Agency (Contract Number RD-83556701), Water Environment Research Foundation, and Washington State University Agricultural Research Center. The authors wish to thank Jingwei Ma, Raul Pelaez Samaniego, Gopi Krishna Kafle, and Alex William Dunsmoor for their skillful technical assistance. 


\section{References}

APHA. (2005). Standard methods for the examination of water and wastewater. American Public Health Association (APHA): Washington, DC, USA.

Barker, J. C. (1996). Lagoon design and management for livestock waste treatment and storage. North Carolina Cooperative Extension Service.

BAO, T., SUN, T., SUN, L., \& ZHANG, H. (2012). Advances in Research of Biotransformation Technology to Dairy Manure Resources Utilization. Journal of Shenyang University (Natural Science), 6, 003.

Buffiere, P., Loisel, D., Bernet, N., \& Delgenes, J. P. (2006). Towards new indicators for the prediction of solid waste anaerobic digestion properties. Water Science and Technology, 53(8), 233-241.

Burton, C. H. (2007). The potential contribution of separation technologies to the management of livestock manure. Livestock Science, 112(3), 208-216.

Chandler, J. A., Jewell, W. J., Gossett, J. M., Van Soest, P. J., \& Robertson, J. B. (1980, January). Predicting methane fermentation biodegradability. In Biotechnol. Bioeng. Symp.;(United States) (Vol. 10, No. CONF-791072-). Cornell Univ., Ithaca, NY.

Chastain, J. P., Vanotti, M. B., \& Wingfield, M. M. (2001). Effectiveness of liquid-solid separation for treatment of flushed dairy manure: a case study. Applied Engineering in Agriculture, 17(3), 343.

De Jong, R., Drury, C. F., Yang, J. Y., \& Campbell, C. A. (2009). Risk of water contamination by nitrogen in Canada as estimated by the IROWC-N model. Journal of environmental management, 90(10), 3169-3181.

EPA. (2013). Inventory of U.S. Greenhouse Gas Emissions and Sinks: 1990-2011. EPA 430-R-13-001, U.S. Environmental Protection Agency, 1200 Pennsylvania Ave., N.W. Washington, DC 20460 U.S.A.

Frear, C., Wang, Z. W., Li, C., \& Chen, S. (2011). Biogas potential and microbial population distributions in flushed dairy manure and implications on anaerobic digestion technology. Journal of Chemical Technology and Biotechnology, 86(1), 145-152.

Fu, Z., Yang, F., An, Y., \& Xue, Y. (2009). Simultaneous nitrification and denitrification coupled with phosphorus removal in an modified anoxic/oxic-membrane bioreactor (A/O-MBR). Biochemical Engineering Journal, 43(2), 191-196.

Hara, A., \& Radin, N. S. (1978). Lipid extraction of tissues with a low-toxicity solvent. Analytical biochemistry, 90(1), 420-426. 
Heathwaite, L., Sharpley, A., \& Gburek, W. (2000). A conceptual approach for integrating phosphorus and nitrogen management at watershed scales. Journal of Environmental Quality, 29(1), 158-166.

Kafle, G. K., \& Chen, L. (2016). Comparison on batch anaerobic digestion of five different livestock manures and prediction of biochemical methane potential (BMP) using different statistical models. Waste Management, 48, 492-502.

Kafle, G. K., \& Kim, S. H. (2012). Kinetic study of the anaerobic digestion of swine manure at mesophilic temperature: a lab scale batch operation. Journal of Biosystems Engineering, 37(4), 233-244.

Kristensen, E., Ahmed, S. I., \& Devol, A. H. (1995). Aerobic and anaerobic decomposition of organic matter in marine sediment: which is fastest?.Limnology and Oceanography, 40(8), 1430-1437.

Lanyon, L. E. (1994). Dairy manure and plant nutrient management issues affecting water quality and the dairy industry. Journal of Dairy Science,77(7), 1999-2007.

Ledda, C., Schievano, A., Salati, S., \& Adani, F. (2013). Nitrogen and water recovery from animal slurries by a new integrated ultrafiltration, reverse osmosis and cold stripping process: A case study. Water research, 47(16), 6157-6166.

Lesteur, M., Latrille, E., Maurel, V. B., Roger, J. M., Gonzalez, C., Junqua, G., \& Steyer, J. P. (2011). First step towards a fast analytical method for the determination of biochemical methane potential of solid wastes by near infrared spectroscopy. Bioresource technology, 102(3), 2280-2288.

Li, C., Salas, W., Zhang, R., Krauter, C., Rotz, A., \& Mitloehner, F. (2012). ManureDNDC: a biogeochemical process model for quantifying greenhouse gas and ammonia emissions from livestock manure systems. Nutrient Cycling in Agroecosystems, 93(2), 163-200.

Metcalf, E., \& EDDY, M. (2014). Wastewater engineering: treatment and Resource recovery. McGraw-Hill Education, New York.

Menke, L., Troubounis, G., Leitner, B., Knoll, B., \& Theunis, C. (2005). U.S. Patent Application No. 11/318,146.

Molina, J. A. E., Clapp, C. E., Shaffer, M. J., Chichester, F. W., \& Larson, W. E. (1983). NCSOIL, a model of nitrogen and carbon transformations in soil: description, calibration, and behavior. Soil Science Society of America Journal, 47(1), 85-91.

Møller, H. B., Lund, I., \& Sommer, S. G. (2000). Solid-liquid separation of livestock slurry: efficiency and cost. Bioresource Technology, 74(3), 223-229. 
Møller, H. B., Sommer, S. G., \& Ahring, B. K. (2004). Methane productivity of manure, straw and solid fractions of manure. Biomass and bioenergy,26(5), 485-495.

Murwira, H. K., Kirchmann, H., \& Swift, M. J. (1990). The effect of moisture on the decomposition rate of cattle manure. Plant and Soil, 122(2), 197-199.

Ndegwa, P. M., Hristov, A. N., Arogo, J., \& Sheffield, R. E. (2008). A review of ammonia emission mitigation techniques for concentrated animal feeding operations. Biosystems engineering, 100(4), 453-469.

Novak, J. T., Banjade, S., \& Murthy, S. N. (2011). Combined anaerobic and aerobic digestion for increased solids reduction and nitrogen removal. Water research, 45(2), 618-624.

NRCS. (2015). Agricultural Waste Management Systems in Agricultural Waste Management Field Handbook. Natural resources Conservation services. United States department of Agriculture. Available at http://www.nrcs.usda.gov/wps/portal/nrcs/detailfull/national/water/?\&cid=stelprdb104593 5 Accessed 3/3/2016

Olesen, J. E., Weiske, A., Asman, W. A., Weisbjerg, M. R., Djurhuus, J., \& Schelde, K. (2004). FarmGHG. A model for estimating greenhouse gas emissions from livestock farms: documentation. DJF Internal Report; No. 202. Aarhus University, Denmark. Paul, E. A., Harris, D., Collins, H. P., Schulthess, U., \& Robertson, G. P. (1999). Evolution of $\mathrm{CO} 2$ and soil carbon dynamics in biologically managed, row-crop agroecosystems. Applied Soil Ecology, 11(1), 53-65.

Paul, E. A., Collins, H. P., \& Leavitt, S. W. (2001). Dynamics of resistant soil carbon of Midwestern agricultural soils measured by naturally occurring $14 \mathrm{C}$ abundance. Geoderma, 104(3), 239-256.

Pham CH, Triolo JM, Cu TTT, Pedersen L, Sommer SG. (2013) Validation and recommendation of methods to measure biogas production potential of animal manure. Asian-Australasian J Anim Sci. 26:864-73.

Phetteplace, H. W., Johnson, D. E., \& Seidl, A. F. (2001). Greenhouse gas emissions from simulated beef and dairy livestock systems in the United States. Nutrient cycling in agroecosystems, 60(1-3), 99-102.

Robertson, G. P., Wedin, D., Groffman, P. M., Blair, J. M., Holland, E. A., Nedelhoffer, K. J., ... \& Sollins, P. (1999). Soil carbon and nitrogen availability. Nitrogen mineralization, nitrification and soil respiration potentials. Standard soil methods for long-term ecological research., 258-271. 
Rotz, C. A., Corson, M. C., Chianese, D. C., \& Coiner, C. U. (2009). The Integrated Farm System Model-Reference Manual 3.0. Pasture Systems and Watershed Management Research Unit. Agricultural Research Service. United States Department of Agriculture. Available at:

http://www.ars.usda.gov/sp2userfiles/place/80700000/ifsmreference.pdf_Accessed $3 / 3 / 2016$

Rotz, C. A., Montes, F., \& Chianese, D. S. (2010). The carbon footprint of dairy production systems through partial life cycle assessment. Journal of dairy science, 93(3), 1266-1282.

SAS Institute. (2008) SAS Proprietary Software 9.2 (TS2M2). SAS Institute, Inc., Cary, NC.

Saviozzi, A., Levi-Minzi, R., \& Riffaldi, R. (1993). Mineralization parameters from organic materials added to soil as a function of their chemical composition. Bioresource technology, 45(2), 131-135.

Sims, J. T., Bergström, L., Bowman, B. T., \& Oenema, O. (2005). Nutrient management for intensive animal agriculture: policies and practices for sustainability. Soil Use and Management, 21(1), 141-151.

Smith, J. L., Schnabel, R., McNeal, B. L., \& Campbell, G. S. (1980). Potential errors in the first-order model for estimating soil nitrogen mineralization potentials. Soil Science Society of America Journal, 44(5), 996-1000.

Sollins, P., Glassman, C., Paul, E.A., Swanston, C., Lajtha, K., Heil. J.W., and Elliot, E.T., (1999) Soil Carbon and Nitrogen: Polls and Fractions. Standard soil methods for long-term ecological research., 88-105.

Spellman, F. R., \& Whiting, N. E. (2007). Environmental management of concentrated animal feeding operations (CAFOs). CRC Press, Florida.

Stöckle, C. O., Donatelli, M., \& Nelson, R. (2003). CropSyst, a cropping systems simulation model. European journal of agronomy, 18(3), 289-307.

Thomsen, I. K., Olesen, J. E., Møller, H. B., Sørensen, P., \& Christensen, B. T. (2013). Carbon dynamics and retention in soil after anaerobic digestion of dairy cattle feed and faeces. Soil Biology and Biochemistry, 58, 82-87.

Triolo, J. M., Sommer, S. G., Møller, H. B., Weisbjerg, M. R., \& Jiang, X. Y. (2011). A new algorithm to characterize biodegradability of biomass during anaerobic digestion: influence of lignin concentration on methane production potential. Bioresource technology, 102(20), 9395-9402. 
Tritt, W. P., \& Kang, H. (1991). Ultimate biodegradability and decay rates of cow paunch manure under anaerobic conditions. Bioresource technology, 36(2), 161-165.

USDA (2011) U.S. Agriculture and Forestry Greenhouse Gas Inventory: 1990-2008. Technical Bulletin No. 1930. Climate Change Program Office, Office of the Chief Economist, U.S. Department of Agriculture, Washington, DC.

Uslar, N. (2010). Gaseous emissions and nutrient fate modeling in dairy operations (Doctoral dissertation, Washington State University). Available at https://research.wsulibs.wsu.edu/xm/ui/handle/2376/2812 Accessed 3/3/2016

Vanotti, M. B., \& Hunt, P. G. (1999). Solids and nutrient removal from flushed swine manure using polyacrylamides. Transactions of the ASAE,42(6), 1833-1840.

Uludag-Demirer, S., Demirer, G. N., Frear, C., \& Chen, S. (2008). Anaerobic digestion of dairy manure with enhanced ammonia removal. Journal of environmental management, 86(1), 193-200. 